\title{
Studies on Endophytic Fungi of Calotropis Procera (L.) R.Br. with A View to Their Antimicrobial and Antioxidant Actvities Mediated by Extracellular Synthesised Silver Nanoparticles.
}

\author{
Debjani Roy Chowdhury ${ }^{1}$, Swapan Kumar Chatterjee ${ }^{2}$ and Subhash Kanti Roy ${ }^{1 \#}$ \\ ${ }^{I}$ PG Department of Biotechnology and Biochemistry, Oriental Institute of Science and Technology (Vidyasagar \\ University), Dewandighi, Katwa Road, Burdwan-02, West Bengal, India. \\ ${ }^{2} P G$ Department of Botany, Hooghly Mohsin College, Chinsurah, Hooghly, West Bengal, India \\ \# Author for correspondence : Email- roy.subhash@ @rediffmail.com
}

\begin{abstract}
Isolation and characterisation of four predominant endophytic bacteria namely, Pencillium sp., Alternaria sp., Aspergillus sp. and Cladosporium sp. from different parts of Calotropis procera plant has been conducted in summer season. Among four isolated fungi Alternaria sp. exhibited the highest (33.33\%) colonisation frequency followed by Penicillum sp. (16.66\%), Aspergillus sp.(8.33\%) and Cladosporium sp. ( $8.33 \%)$. The production and evaluation of "green synthesised AgNPs" has been carried out with the use of fungal cell free extract of four endophytic fungi understudy. The synthesis of AgNPs has been detected by colour change of the solution follwed by UV -Visible spectroscopy and FTIR spectroscopy.The synthesis of AgNPs was maximum in Penicllium sp. followed by Alternaria sp. The antibacterial activity of four fungal cell free extract as well as with AgNPs has conducted against two pathogenic bacteria, E.coli and Bacillus subtilis. Among them Penicillium sp. shows significant antibacterial activity against E.coli rather than Bacillus subtilis. Total phenol content and antioxidant properties of four fungi revealed significant result. The maximum phenol content (83 $\mu \mathrm{g} / \mathrm{l})$ and maximum antioxidant assay $(28 \mu \mathrm{g} / \mathrm{ml})$ has obtained in fungal cell free extract of Alternaria sp.
\end{abstract}

Keywords: Calotropis procera, endophytic fungi, colonisation frequency, green synthesised AgNPs, antimicrobial and antioxidant properties.

\section{Introduction}

The demand for new bioactive compounds used in medicine, industry and agriculture has increased in recent times. Since plants have been a major source of bioactive compounds for drug discovery, attention has more recently been given to endophytes, as these microorganisms demonstrate great potential sources for new such compounds ( Strobel and Daisy, 2003). Endophytes are microbes which colonize at living internal tissues of plants without causing any harm to their hosts (Becon and White 2001). Almost all groups of microorganisms have been found in endophytic association with plants such as fungi, bacteria or actinomycetes. These endophytes protect their hosts from infectious agents and adverse conditions by secreting bioactive secondary metabolites (Strobel and Daisy, 2003). Endophytes, found ubiquitous in all plant species in the world, contribute to their host plants by producing plenty of substances that provide protection and ultimately survival value to the plant. Many researchers have proven that endophyte is a new and potential source of novel natural products for exploitation in modern medicine, agriculture and industry (Strobel and Daisy, 2003). The endophytic fungi plays an important physiological (Malinowski, 2006) and ecological (Tintjer and Rudger, 2006; Malinowski , 2004) roles in their host life.

Many endophytic fungi have been reported to produce novel antibacterial, antifungal, antiviral, antiinflammatory, antitumor and other compounds belonging to the alkaloids, steroids, flavonoid and terpenoids derivatives and other structure types ( Guo et al., 2010 ,Yu et al., 2010, Aly et al., 2011). The pharmaceutical and medicinal concerns of new drugs are the toxicity of these prospective compounds to human tissues. Since, the plant tissue where the endophytes exist is a eukaryotic system, it would appear that the secondary metabolites produced by the endophytes may have reduced cell toxicity; otherwise, death of the host tissue (Strobel and Daisy, 2003) may occur. Thus, the host itself has naturally served as a selection system for microbes having bioactive molecules with reduced toxicity towards higher organisms.

Nanoparticles produced by a bio-enzymatic process are far superior, in several ways, to those particles produced by chemical methods despite the fact that the latter methods are able to produce large quantities of nanoparticles with a defined size and shape in a relatively short time. With an enzymatic process, the use of expensive chemicals is eliminated, and the more acceptable "green" route is not as energy intensive as the chemical method and is also environment friendly. Nanoparticles are biosynthesized when the microorganisms grab target ions from their environment and then turn the metal ions into the element metal through enzymes 
Studies on Endophytic Fungi of Calotropis Procera (L.) R.Br. with A View to Their Antimicrobial....

generated by the cell activities. It can be classified into intracellular and extracellular synthesis according to the location where nanoparticles are formed (Sunkar and Nachiyar, 2012 ; Simkiss and Wilburr ,1989).

The multi-resistant pathogens due to antigenic shifts and / or drifts are ineffectively managed with current medications. This resistance to medication by pathogens has become a serious problem in public health and therefore mandating the need to develop new bacteriocides and virocides. Silver nanoparticles (AgNPs), having a long history of general use as an antiseptic and disinfectant, are able to interact with disulfide bonds of the glycoprotein / protein contents of microorganisms such as viruses, bacteria (Furr et al., 1994, Sondi and Sondi, 2004) and fungi (Gajbhiye et al., 2009). Both silver nanoparticles and silver ions can change the three dimensional structure of proteins by interfering with $\mathrm{S}-\mathrm{S}$ bonds and block the functional operations of the microorganism (Chunj et al ., 2004, Liau et al., 1997).

The interference of endophytes with nanoparticles is relatively new and is expected to have significant impact. Fungal endophytes are reported to secrete diverse group of biomolecules extracellularly which are capable of reducing metal salts at rapid scale under optimized conditions. One such endophyte is isolated from healthy leaf of Andrographis paniculata and employed for rapid synthesis of silver nanoparticles. The synthesized nanoparticles were evaluated for bactericidal activity against significant human pathogens ( Azmath et al.,2016).

Fungi have some distinct advantages when used as nanofactories for NP production ( Volesky and Holan,1995). Ag Nanoparticles were tested against various human pathogens viz. Gram negative E.coli, K. pneumoinae, Pseudomonas fluroescens and Gram positive S. aureus and B. subtilis and showed good antimicrobial activity (Bansal et al., 2003). In particular, silver nanoparticles (AgNPs) have attracted much attention in the scientific field ( Jana and Pal , 2007; Stiufiuc et al., 2013, Szmacinski 2008). Silver has always been used against various diseases; in the past it was found to use as an antiseptic and antimicrobial against Gram positive and Gram negative bacteria ( Lazar 2011, Donlan and Costerton 2002, Taraszkiewicz 2013 ) due to its low cytotoxicity ( Biel et al., 2011). AgNPs were considered, in recent years, particularly attractive for the production of a new class of antimicrobials ( Dos Santos et al., 2014, Rai et al ., 2014) to opening up a completely new way to combat a wide range of bacterial pathogens.

Calotropis procera ( Linn. ) R.Br. (family Asclepiadaceae) also known as Giant Milkweed/ Swallow Wort and Aakanda, Madaar of India. The plant is used in many Ayurvedic formulations like Arkelavana. The medicinal potential of Calotropis procera has been known to traditional systems of medicine for a while. The use of the plants, plant extracts, and pure compounds isolated from natural sources has always provided a foundation for modern pharmaceutical compounds (Trease and Evans 2005). Calotropis procera is a well known plant and has been traditionally used for diarrhea, stomacic, sinus, fistula, and skin disease, ( Alikhan and Khanum 2005, Raghubir et al., 1999) and the leaf part is used to treat jaundice. Calotropis gigantea R.Br. a widely used medicinal plant in India, were exploited for endophytes as a possible source of bioactive compounds (Selvanathan et al., 2011).

There are scanty reports on fungal endophytes of Calotropis procera with special reference to their animcrobial, antioxidant properties and green synthesis of AgNPs using the cell free extracts of that fungi in West Bengal. The biodiversity study of fungal endophytes of Calotropis procera form Burdwan district of West Bengal had conducted by Roy Chowdhury et al., 2014. Keeping this background information the present study have undertaken to isolate and identify fungi from different parts of Calotropis procera mainly in summer season and to analyse their antibacterial, antioxidant activities with a view to production of "green synthesis" (Bansal et al., 2014) of nanoparicles mainly AgNPs.

\section{Collection and Preperation of Plant Materials:}

\section{Materials and Methods}

Tissue samples of leaves, stems and roots were collected from healthy Calotropis procera R.Br. plant from outskirts of Burdwan town. The leaves, stems and roots were washed under running tap water thoroughly for 1 hour, and then cut into small pieces. The samples were surface sterilized by modified method of Dobarnic et al.,1995, then the samples were immersed in ethanol $(70 \% \mathrm{v} / \mathrm{v})$ for 1 minute, followed by treatment with sodium hypochlorite $(4 \% \mathrm{v} / \mathrm{v})$ for 2 minutes and then rinsed with sterile double distilled water for 1 minute.

\section{Isolation and development of Pure Culture:}

Isolation of endophytic fungi from Calotropis procera was carried out using the protocol described by Strobel and Daisy, 2003; Roy Chowdhury et al., 2014 with slight modifications. The surface sterilized segments were placed in Petri-dishes containing Potato Dextrose Agar (PDA) media supplemented with tetracycline 100 units $/ \mathrm{ml}$ concentration. The Petri-dishes were sealed using parafilm and incubated at $26 \pm 1{ }^{\circ} \mathrm{C}$ for 7 days. The Petri-dishes were monitored everyday to check the growth of endophytic fungal colonies from the plant sample. The isolated pure colony were then subculture to PDA slants media for preservation of fungal isolates and were stored at $4^{\circ} \mathrm{C}$ for further studies. 
Studies on Endophytic Fungi of Calotropis Procera (L.) R.Br. with A View to Their Antimicrobial....

\section{Calculation of colonizing frequency:}

The isolated endophytic fungal strains were identified based on their macro and microscopic morphology and by using standard monographs, following the description as reported by Roy Chowdhury et al., 2014. The colonization frequency (CF \%) of each endophytic fungi was calculated and determined using the following formula (Hata and Futtai, 1995, RoyChowdhury et al., 2014):

$$
\text { Colonization frequency }(\%)=\begin{gathered}
\text { Number of segment colonized by fungi } \\
\text { Total number of segment observed }
\end{gathered}
$$

\section{Preparation of fungal cell free extract:}

Crude fungal cell free extract was prepared using the protocol of Radji et al., 2011. Prospective endophytic fungal isolates were inoculated into $250 \mathrm{ml}$ Erlenmeyer flasks containing $100 \mathrm{ml}$ of potato dextrose broth and incubated at room temperature for 21 days under stationary conditions with intermittent shaking. The broth culture was filtered to separate the mycelia and filtrate. To the filtrate equal volume of ethyl acetate was added, mixed well for 30 minutes and kept for 15 minutes till the two clear immiscible layers formed. The upper layer of ethyl acetate containing the bioactive compounds was separated using separating funnel. And same extraction has carried out without using ethyl acetate also.

\section{Biomass preparation and biosynthesis of AgNPs:}

Based on literature and other morphotaxonomic features selected isolate was identified, and used in the study as a reducing agent for the aqueous silver ion solution. The fungal biomass used for biosynthetic experiment was grown aerobically in liquid medium containing potato dextrose broth. The flasks were inoculated by grown fungus (taking from slant) and incubated at $28^{\circ} \mathrm{C}$ on a rotary shaker $(150 \mathrm{rpm})$ for a week. After incubation the biomass was filtered using Whatman filter paper No.1 and then washed extensively with sterile double distilled water to remove any medium component. Typically $10 \mathrm{~g}$ of biomass were brought into contact with $50 \mathrm{ml}$ of sterile double distilled water for $72 \mathrm{hrs}$ at $27^{\circ} \mathrm{C}$ in an Erlenmeyer flask and agitated at 150 $\mathrm{rpm}$. After incubation the cell free filtrate was obtained by filtering with Whatman filter paper No1. Fermented cell free extract of isolated endophytic fungi were treated with equal volume of $1 \mathrm{mM}$ of $\mathrm{AgNO}_{3}$ (AR Grade) and incubated at different temperatures ranging from 30 to $80^{\circ} \mathrm{C}$ and $\mathrm{pH}$ of the reaction mixture was varied from acidic to alkaline. Samples were monitored periodically for the synthesis of nanoparticles with the aid of UV-Visible spectrophotometer operating at a resolution of $1 \mathrm{~nm}$ (Baker et al., 2014).

\section{Antibacterial activity of Fungal cell free extract and AgNPs :}

Antibacterial activity of metabolites obtained from cell free extracts of isolated endophytic fungi was screened against pathogenic bacteria using agar well diffusion method (Newyork et al .,1972). Two bacteria namely B. subtilis (Gram positive) and E. coli (Gram negative) were obtained from our Institute Microbial Type culture collection which was initially procured from MTCC type culture, Chandigarh, grown on nutrient broth media and incubated at $37^{\circ} \mathrm{C}$ for 24 hours in bacteriological incubator for evaluation of antimicrobial activity. Sterile double distilled water was used as standard for this assay. Potato Dextrose Agar plates were inoculated with overnight grown culture of each bacterial suspension by evenly spreading out with sterile Borosil glass spreader. The agar wells were prepared by scooping out the media with a sterile cork borer ( $6 \mathrm{~mm}$ in diameter). The wells were then filled with 20,40 , and $60 \mu 1$ of fungal crude extract which was already dissolved in DMSO. The plates were then incubated at $37^{\circ} \mathrm{C}$ for $24 \mathrm{~h}$ and the zone of inhibition was recorded.

The potential of silver nanoparticles as effective antimicrobial agents have been well appreciated. Hence the silver nanoparticles were checked for their antibacterial activity using the agar well diffusion assay method against two pathogenic bacteria B. subtilis (Gram positive) and E. coli (Gram negative). The respective test organisms were prepared by spreading $150 \mu \mathrm{l}$ of revived culture on the nutrient agar plate, 4 wells were cut with the help of a sterilized stainless steel cork borer into which different concentrations of AgNPs solution (20, 40 , and $60 \mu \mathrm{l})$ and control solution $\left(20 \mu \mathrm{l}\right.$ without $\left.\mathrm{AgNO}_{3}\right)$ was loaded and incubated at $37^{\circ} \mathrm{C}$ for $24 \mathrm{~h}$. The plates were then examined for evidence of zones of inhibition, which appear as a clear area around the wells. The diameter of such zones of inhibition was measured for each organism and expressed in millimeter.

\section{Total phenol content:}

The total phenolic compounds content in the extract were determined according to the method of Singleton and Rossi as cited in Coruh et al ., 2007, with some modifications to $1.0 \mathrm{ml}$ of methanol extracts, $2 \mathrm{ml}$ of $3 \%(\mathrm{w} / \mathrm{v})$ sodium carbonate solution was added followed by vigorous vortexing. After $5 \mathrm{~min} 0.1 \mathrm{ml}$ of 1:1 diluted Folin reagent to the standard solution of Gallic acid $(0.05-0.3 \mathrm{mg} / \mathrm{ml})$ was added, then the tubes were 
Studies on Endophytic Fungi of Calotropis Procera (L.) R.Br. with A View to Their Antimicrobial....

incubated at room temperature for 30 mins. and the absorbance was measured at $720 \mathrm{~nm}$. The total phenol content in the extracts was expressed as Gallic acid equivalent in $\mu \mathrm{g} / \mathrm{ml}$.

\section{Total antioxidant activity:}

Samples or standard $(1 \mathrm{ml})$ was mixed with $2 \mathrm{ml}$ each of ammonium molybdate $(4 \mathrm{mM})$, sodium phosphate $(28 \mathrm{mM})$ and sulphuric acid $1(\mathrm{~N})$. The ascorbic acid ( AR grade) standard are used at a concentration of $500 \mu \mathrm{g} / \mathrm{ml}$. All the reaction mixtures were incubated at $30^{\circ} \mathrm{C}$ for $60 \mathrm{~min}$. The absorbance was measured at 665 $\mathrm{nm}$ wavelength. Reducing capacity of the extract has been expressed as the ascorbic acid equivalents (Prielo et al .,1999).

\section{Characterization of Silver Nanoparticles: \\ Visual observation:}

The formation of AgNps was preliminarily confirmed by visual observation of color change from pale white to reddish brown.This is due to the surface Plasmon resonance of the silver nanoparticles (Krishnaraj et al., 2010).

\section{$U V$-Visible Spectroscopy:}

Silver nanoparticle synthesis was further confirmed by the sharp peaks given by the AgNPs in the visible region in UV - Vis spectrum of the reacting solution using Perkin-Elmer Lamda-45 Spectrophotometer, in a $1 \mathrm{~cm}$ path quartz cell at a resolution of $1 \mathrm{~nm}$ in the range of 250 to $800 \mathrm{~nm}$.

\section{Fourier Transform Infrared Spectroscopy (FTIR):}

The AgNps synthesized were air dried at room temperature and were subjected to FTIR analysis in the range of 500 to $4000 \mathrm{~cm}^{-1}$. For detection of probable functional groups in biomolecules present in the plant extract responsible for reduction, capping, and effective stabilization of the AgNps were recorded using FTIR Spectrophotometer. The probable biomolecules involved in the synthesis and stabilization of nanoparticles was recorded by FTIR spectrum using FTIR Nicolet Avatar 660 (Nicolet, USA) (Sunkar and Nachiyar 2012).

\section{Isolation of Endophytic Fungi:}

\section{Results and Discussion}

After seven days of incubation at $26 \pm 1^{0} \mathrm{C}$ of the different plant parts (surface sterilized root, stem and leaf segment of Calotropis procera, cottony mass from each inoculated sample were emerges out from the medium surface ( Fig:1). Out of the three palnt parts so far tested, the leaf segment showed better response in terms of fungal colony development.

\section{Identification of endophytic fungi:}

The isolated culture of endophytic fungal strains were then identified by their colony morphology followed by microscopical observation as carried out by Roy Chowdhury et al .,2014. The predominant endophytic fungi isolated from root, stem and leaf of Calotropis procera were manily of Penicillium sp, Aspergillus sp, Alternaria sp and Cladosporium sp. The colony morphology, microscopical features and pure culture of two identified strains of Penicillium sp and Alternaria sp are shown in Figure 1, as their colonisation frequency is high (Table 1), these two fungal strains has considered for further investigation in this study.
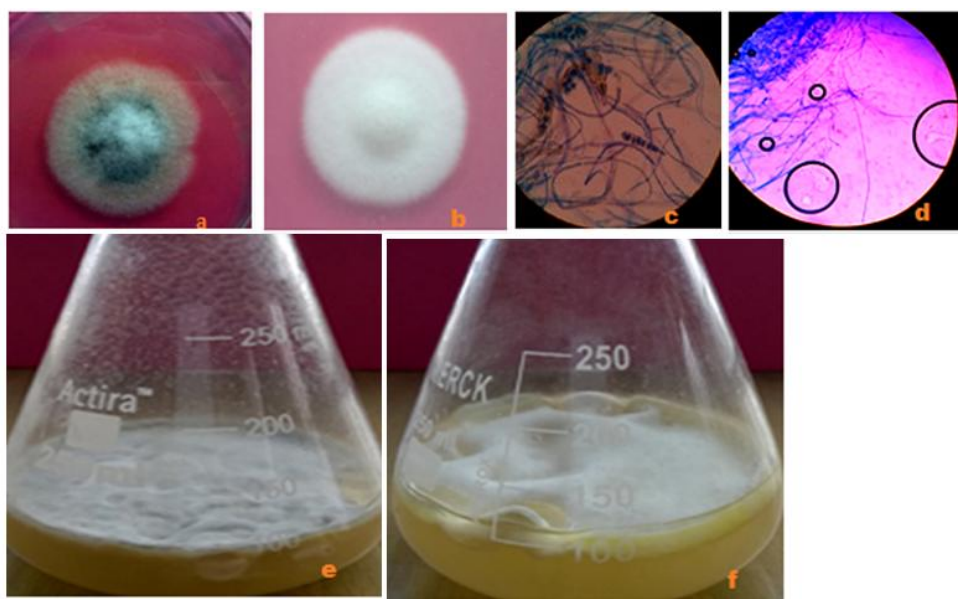

Figure 1: Colony morphology ; Microphotograph of and Pure culture of Alternaria sp, (a,c,e) and Penicillium $\operatorname{sp}(\mathrm{b}, \mathrm{d}, \mathrm{f})$ 
Studies on Endophytic Fungi of Calotropis Procera (L.) R.Br. with A View to Their Antimicrobial....

\section{Colonizatoin frequency of Isolated Fungi:}

Colonization frequency of four identified fungi namely Penicillium sp, Aspergillus sp, Alternaria sp and Cladosporium from root, stem and leaf segment of Calotropis procera has been determined using the formula as stated in materials method section. It has evident from the result that this frequency of four stated fungi is remarkable from leaf segment, and least dominant in stem and little or no in root segment. Among four fungi, colonization frequency is highest (33.33\%) in Penicillium sp, medium in (16.66 \%), Alternaria sp, and low ( $8.33 \%$ ) in Aspergillus sp and Cladosporium sp. of leaf segment ( Table 1, Figure 2). However, the colonisation frequency of these four fungi from same medicinal plants leaf as investigated earlier by same research group (Roy Chowdhury et al., 2014) are somewhat different. The highest colonisation frequency (40\%) has observed in Alternaria sp. followed by Aspergillus sp. $(20 \%)$, Penicillium sp $(13.3 \%)$ and Cladosporium sp.( $6.7 \%)$. This variation is resulted due to seasonal changes, as the present study has performed mainly by collecting the plant materials in summer season.

Table 1: Colonization frequency of endophytic fungi isolated from leaf segment of Calotropis procera

\begin{tabular}{|c|l|c|l|l|l|}
\hline SI.No. & Endophytic Fungi Isolated & Plant parts & $\begin{array}{l}\text { Total No. of } \\
\text { colony }\end{array}$ & $\begin{array}{l}\text { No. of } \\
\text { colonies } \\
\text { grown }\end{array}$ & $\begin{array}{l}\text { \% of } \\
\text { Colonization } \\
\text { Frequency }\end{array}$ \\
\hline 1 & Alternaria sp. & Leaf & 2 & 8 & 16.66 \\
\hline 2 & Penicillium sp. & Leaf & 4 & 14 & 33.33 \\
\hline 3 & Aspergillus niger & Leaf & 1 & 6 & 8.33 \\
\hline 4 & Cladosporium sp. & Leaf & 1 & 5 & 8.33 \\
\hline
\end{tabular}

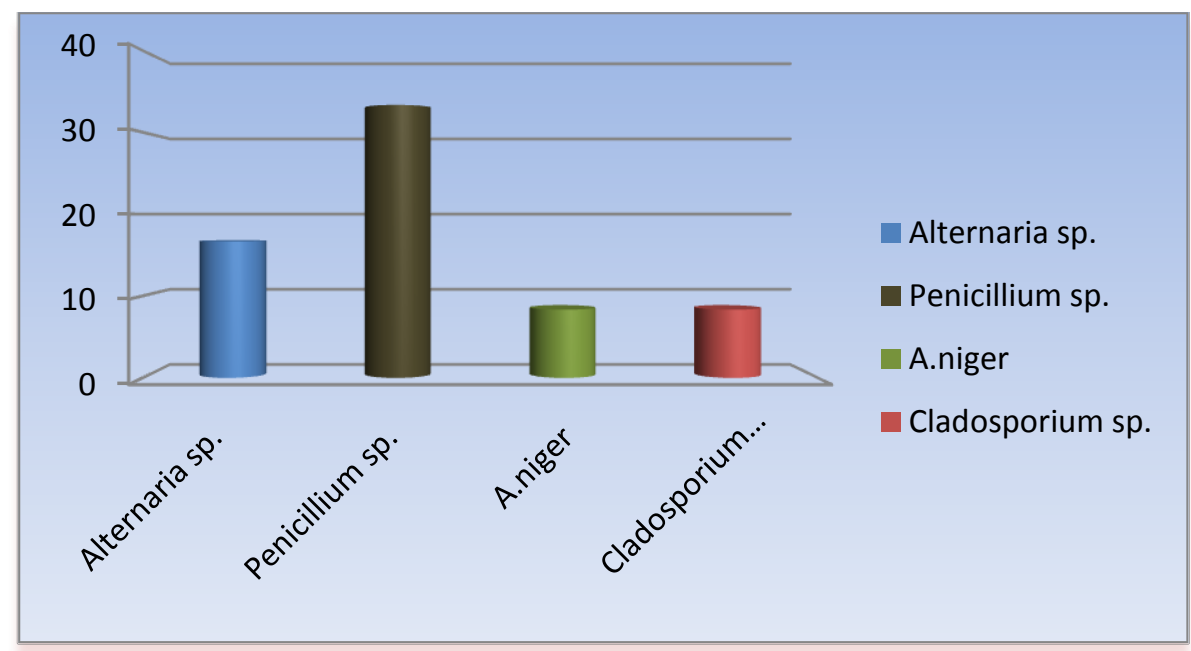

Figure 2: Colonization Frequency (\%) of endophytic Fungi isolated from Calotropis procera

Antimicrobial activity of fungal cell free extract and Mycosynthesised AgNPs : Antibacterial activity of cell free extract as well as mycosynthesised AgNPs of four endophytic fungi understudy has been tested against two pathogenic bacteria namely E.coli and Bacillus subtilis. The fungal cell free extract showed little or negligible antibacterial activity against both bacteria. Penicillum synthesized AgNPs extract showed maximum inhibition zone $(23 \mathrm{~mm}$ in diameter, well number 4 of figure $3 \mathrm{a})$ against E.coli, and $(20 \mathrm{~mm}$ in diameter, well number 4 of figure $3 \mathrm{~b}$ ) against Bacillus subtilis (Fig. 3). Whereas Alternaria synthesised AgNPs showed maximum inhibition zone ( $21 \mathrm{~mm}$ in diameter, well number 4 of figure $3 \mathrm{c}$ ) against E.coli and $(20 \mathrm{~mm}$ in diameter, well number 4 of figure 3d) against Bacillus subtilis (Fig.3). The result indicated that since E.coli is a Gram(-) bacteria it is more susceptible to silver nanoparticles and Bacillus subtilis being a Gram (+) bacteria it is more resistance to AgNPs. These findings are in agreement with previous studies that examined antibacterial activity of AgNPs (Kim et al., 2007). The correlation between the bactericidal effect and AgNP concentrations is bacterial class dependent (Chernousova and Epple, 2013). It is observed that the inhibition of bacterial growth is directly proportional to the concentration or amount of fungal cell free extract containing with silver nanoparticle. This is particularly important in the case of Gram negative bacteria where numerous studies have observed the adhesion and accumulation of AgNPs to the bacterial surface. Many studies have reported that AgNPs can damage cell membranes leading to structural changes, which render bacteria more permeable (Lazar V 2011, Periasamy et al., 2012). 

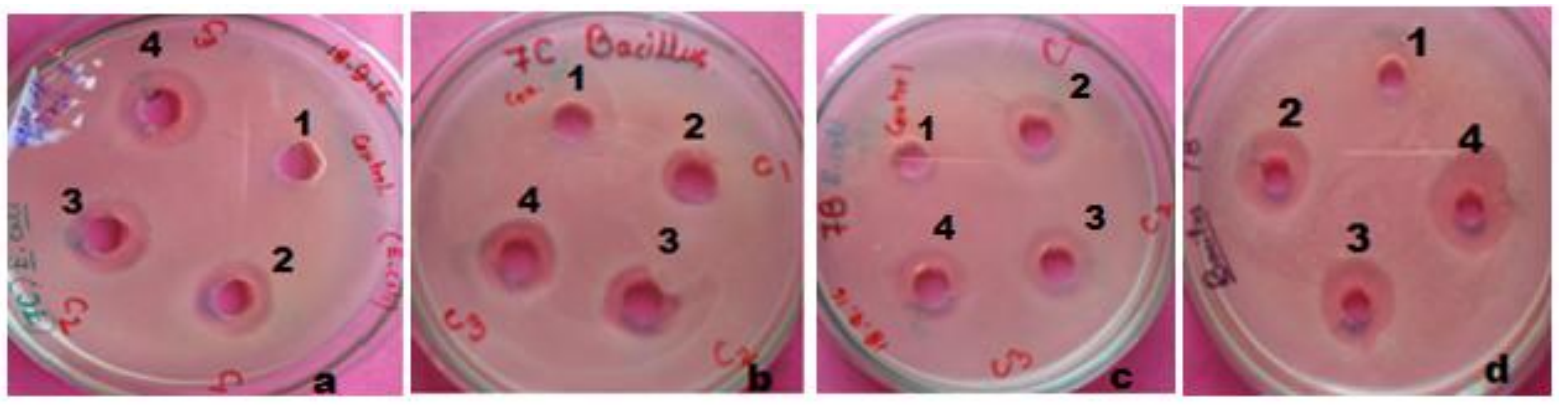

Figure 3: Antibacterial activity of (a) Penicllium synthesised AgNPs against E. coli ,(b) Penicllium synthesised AgNPs against B. subtilis (c) Alternaria synthesised AgNPs against E.coli and (d) Alternaria synthesised AgNPs against B. subtilis

\section{Characterization of Silver Nanoparticles: Visual observation:}

After treating the fermentated cell free fungal extract of Penicillium sp. with $1 \mathrm{mM}$ of $\mathrm{AgNO}_{3}$, the pale white colour of extract turned dark brown (Fig: 3), it indicates the formation of AgNPs, while no color change was observed in the absence of AgNPs. This is due to the surface plasmon resonance of the silver nanoparticles (Krishnaraj et al., 2010). The synthesis was rapid and completed within 20 mins. under optimized condition. It was observed that the synthesis was maximum at elevated temperature above $50{ }^{\circ} \mathrm{C}$, as the temperature increased the synthesis was efficient and rapid which confirmed that elevated temperature influenced the synthesis. Similarly alkaline $\mathrm{pH}$ favored the synthesis compared to acidic $\mathrm{pH}$, these results are in accordance with the previous scientific reports (Rashidipour and Heydari 2014). It is reported that Colletotrichum gloeosporioides could efficiently synthesize silver nanoparticles this finding highlights the possible metabolic process and secretion of reducing agent as their extracellular metabolite which is mediating the synthesis (Ravindra and Rajasab, 2014). Another similar study reveals that Penicillium fellutanum a rhizospheric fungus, isolated from mangrove root-soil of Rhizophora annamalayana Kathir, was found to produce silver nanoparticles (Kathiresan et al., 2009).

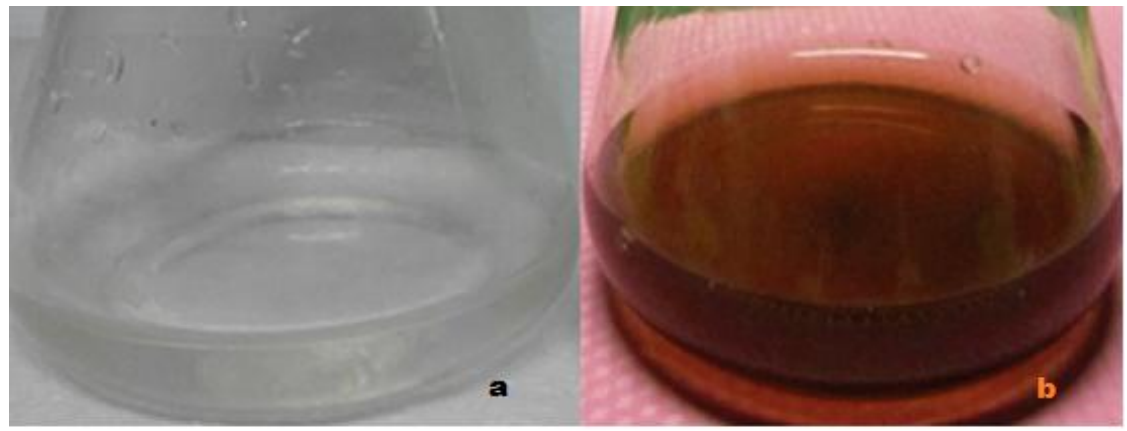

Figure 3: Pale white colour of cell free extract (a), colour change to dark brown in synthesised silver nanoparticle (b).

\section{$U V$-Visible Spectroscopy:}

The extracellular synthesis of AgNps in aqueous solution using four isolated endophytic fungi has been performed, but presence of $\mathrm{AgNO}_{3}$ has detected by recording the absorption spectra only in the extract of Penicillium sp. Synthesized AgNps showed maximum absorbance peak at $420 \mathrm{~nm}$. In the UV-Vis spectrum; a single, strong and broad Surface Plasmon Resonance (SPR) peak was observed at $420 \mathrm{~nm}$ (Fig.3), that confirmed the synthesis of AgNPs. Past studies suggested that a SPR peak located between 410 and 450nm has been observed for AgNPs and might be attributed to spherical nanoparticles (Zaheer and Rafiuddin 2012) . Primary conformation of the AgNPs was carried out by UV- Visible spectrophotometric analysis which showed a strong surface plasmon band at $400 \mathrm{~nm}$ and $423 \mathrm{~nm}$ by GX2-AgNPs and ARA-AgNPs respectively (Sunkar and Nachiyar 2012) which coroborates with our observation. Colletotrichum sp. ALF2-6 culture filtrate reduced silver nitrate and synthesized well dispersed silver nanoparticles which was also confirmed using UV visible spectrum with peak conferring between $300 \mathrm{~nm}$ and $600 \mathrm{~nm}$ and maximum absorbance at $420 \mathrm{~nm}$ as shown in Azmath et al., 2016. 


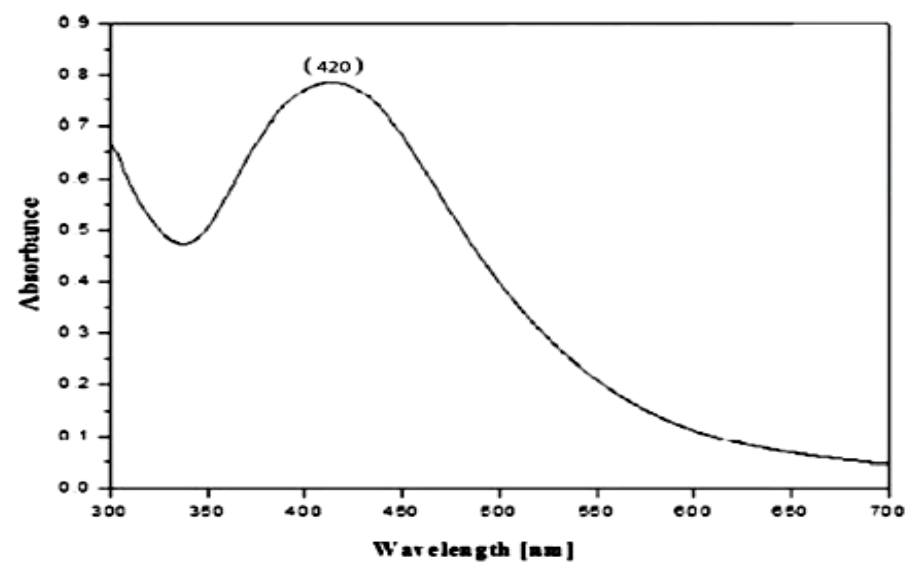

Figure 4: UV-Visible spectra of mycosynthesized silver nanoparticles by Penicillium sp. cell free extract.

\section{Fourier Transform Infrared Spectroscopy (FTIR) analysis:}

FTIR measurement of the dried and powdered sample obtained from Penicillium cell free extract has carried out to identify the possible interaction between silver and bioactive molecules, which may be responsible for synthesis and stabilization of AgNps. The broad peaks at $3429 \mathrm{~cm}^{-1}$ corresponds to the N-H stretching vibrations of amines. The peaks at $2904 \mathrm{~cm}^{-1}$ obtained in the spectra corresponds to the stretching vibrations of carboxylic acids. A small peak at $1650 \mathrm{~cm}^{-1}$ in the AgNPs is indicative of transitional carbonyls. The bands at $1354 \mathrm{~cm}^{-1}$ correspond to the stretch molecule vibration while the peak at $777 \mathrm{~cm}^{-1}$ can be assigned to the aromatic $\mathrm{C}-\mathrm{H}$ out of plane bending vibrations. This FTIR spectrum supports the presence of proteins in the synthesis of silver nanoparticles (Bhainsa KC, D'Souza 2007). Our results of FTIR Spectroscopy also correlates the same observation done by Sunkar and Nachiyar 2013.These results obtained correlate the findings of previous scientific literatures which clearly suggest the metabolic diversity of the fungal communities responsible for mediating the synthesis of the nanoparticles. The extracellular synthesis of silver nanoparticles is more advantageous owing to the fact that it forms easy to downstream the nanoparticles compared to the intracellular synthesis. The obtained nanoparticles will be free from any bio-mass, toxic material and any solvent residues ( Azmath et al., 2016).

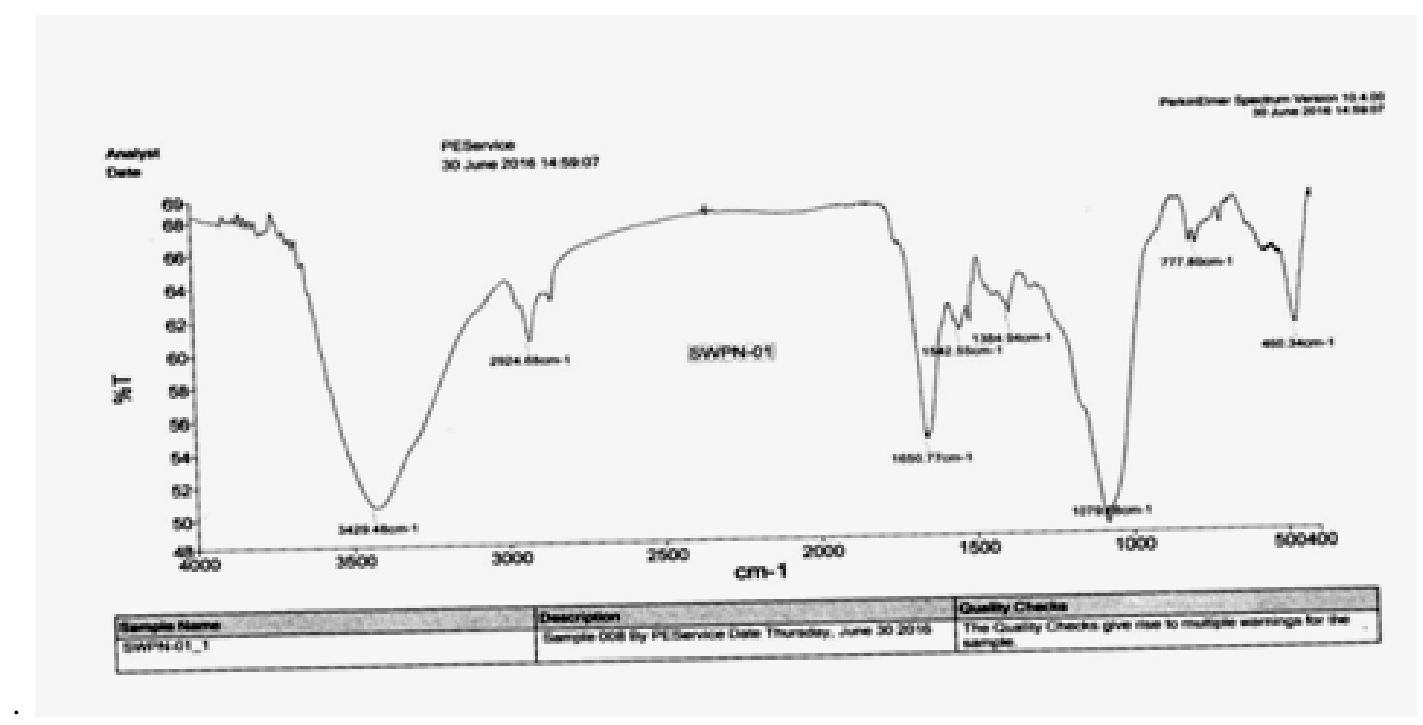

Figure 5: FTIR spectra of mycosynthsied silver nanoparticles.

Total phenol content: Total phenol content of cell free extract of all the four endophytic fungi understudy has been estimated. Among four fungi the total phenol content is highest $(83 \mu \mathrm{g} / \mathrm{ml})$ in Alternaria, moderate ( 65 $\mu \mathrm{g} / \mathrm{ml})$ in Penicillium and lowest $(56 \mu \mathrm{g} / \mathrm{ml})$ exhibited by Aspergillus sp.

Total antioxidant activity: Total antioxidant assay of four fungal cell free extract reveals that Alternaria has the maximum $(28 \mu \mathrm{g} / \mathrm{ml})$ followed by Penicillium $(9 \mu \mathrm{g} / \mathrm{ml})$ has the lowest antioxidant properties. The total phenol and antioxidant content of Alternaria is highest among the entire candidate understudy. The content of phenol, antioxidant and antimicrobial properties are correlated with each othe since phenol itself has strong antioxidant and antmicrobial properties. It has reported that endophytic fungi synthesized a most valued anti cancerous 
drug" Taxol". AgNPs are able to physically interact with the cell surface of various bacteria. Fungal endophytes are a store house of novel secondary metabolites including antibiotic, antioxidant, anticancer and immunosuppressant compounds ( Strobel et al., 2002). Cephalosporium sp., an endophytic fungus isolated from the root of Trachelospermum jasminoides (Apocynaceae) produce a phenolic compound (graphislactone A) with strong free radical scavenging and antioxidant activity (Song et al., 2005). Two antioxidants, pestacin and isopestacin are produced by Pestalotiopsis microspora, an endophytic fungus residing in Terminalia morobensis in Papua New Guinea (Harper et al., 2003). Another antioxidant compound phenylpropanoid amide has been isolated from endophytic fungus Penicillium brasilianum that reside in Melia azedarach (Fill et al., 2010). The results of this study represent that endophytic fungi may serve as a potential source of natural antioxidants.

\section{Conclusion}

"Green synthesized" nanoparticles are environmental friendly, cheap and completely safe, so it can be use extensively. Synthesis of nanoparticles using endophytic fungi isolated from medicinal plants has gaining attention in the recent times as it is a simple and economically benifited method. In this study, AgNps were synthesized extracellularly mainly by Penicillium sp. and Alternaria sp. at room temperature and an elevated temperature. It also played a significant role as a very potential antimicrobial agent. So, it can be use for large scale production of antibiotic and can be used as broad spectrum antibiotic. All the finding of this project indicates about the protective role of endophytes to the host plant. These can be used as potential factories for the production of different novel bioactive secondary metabolites which can be used as pharmaceutical purpose. This investigation reinforced the assumption that endophytes of ethno medicinal plant could be a promising source of silver nanoparticles production as well as anti microbial substance, since the majority of them contains very high amount of "Phenol" which itself a strong antimicrobial agent. The present work will give an insight towrds the sustainable conservation and management of highly valued medicinal palnts as the endophytes plays a remarkable role for production of bioactive compounds. The biosynthesis of nanoparticles by microbes is thought to be clean, nontoxic, and environmentally acceptable "green chemistry" procedures. Further work regarding the isolation and estimation of antimicrobial substances with a focus to the phenolic substances would be undertaken.

\section{Acknowledgement}

The authors are highly acknowledge the facility and support render by Dr. J. B.Medda, Secretary, OIST during this work tenure. Authors are also thankful to Rajesh Chakraborty, Monideepa Banerjee for their assistance to make this study a successful one.

\section{References}

[1]. Strobel G and Daisy B (2003) Bioprospecting for Microbial Endophytes and Their Natural Products. Microbiology and Molecular Biology Reviews. Vol 67(4),491-502

[2]. Becon CW and White JF 2001 Microbial endophytes. Marcel Decker, Inc., New York .

[3]. Malinowski DP and Belesky DP (2006) Ecological importance of Neotyphodium spp. Grass endophytes in agro ecosystems. Grassland science. 52(1): 23-28

[4]. Tintjer T and Rudger AJ ( 2006) Grass-herbivore interaction altered by strains of a native Endophyte. New Phytologist. 170: 513521 .

[5]. Malinowski DP, Zuo H, Belesky DP, Alloush GA. (2004) Evidence for copper binding by extracellular root exudates of tall fescue but not perennial ryegradd infected with Neotyphodium sp., Endophytes. Plant and Soil. 267:1-12

[6]. .Guo B, Wang Y, Sun X, Tang K (2008 ) Bioactive natural products from Endophytes: A Review. Appl Bioch Microbiol. 44: 136142.

[7]. Yu H, Zhang L, Li LZ, Guo C, Li L, Sun W, Qin L. Yu H, Zhang L, Li LZ, Guo C, Li L, Sun W, Qin L. (2010) Recent development and future prospects of antimicrobial metabolites produced by endophytes. Microbial Res. 165: 437-449.

[8]. Aly AH, Debbab A, and Proksch P.( 2011 ) "Fungal endophytes: unique plant inhabitants with great promises. Appl Microbiol \& Biotechnol. 90:1829-1845.

[9]. Swetha Sunkar, Valli Nachiyar C.( 2012 ) Microbial Synthesis and characterization of silver nanoparticles using the Endophytic bacterium Bacillus cereus: A novel source in the benign synthesisis. Global J Medical Research. 12: 43-49.

[10]. Simkiss K, Wilbur KM. (1989) Biomineralization, Academic, New York, NY, USA,.

[11]. Furr JR, Russell AD, Turner TD, Andrews A. (1994) Antibacterial activity of Actisorb Plus, Actisorb and silver nitrate. J Hosp Infect.27:201-208.

[12]. Sondi I and Salopek-Sondi B. (2004) Silver nanoparticles as antimicrobial agent: a case study on E. coli as a model for Gramnegative bacteria. J Colloid Interface Sci. 275:177-182.

[13]. Gajbhiye M, Kesharwani J, Ingle A, Gade A, Rai M. (2009) Fungus-mediated synthesis of silver nanoparticles and their activity against pathogenic fungi in combination with fluconazole. Nanomedicine, 5:382-386.

[14]. Chung YC, Chen IH, Chen CJ. (2008) The surface modification of silver nanoparticles by phosphoryl disulfides for improved biocompatibility and intracellular uptake. Biomaterials.29:1807-1816.

[15]. Liau SY, Read DC, Pugh WJ, Furr JR, Russell AD (1997). Interaction of silver nitrate with readily identifiable groups: relationship to the antibacterial action of silver ions. Lett Appl Microbiol. 25: 279-283.

[16]. Azmath P, Baker S and Rakshith D ( 2016) Mycosynthesis of silver nanoparticles bearing antibacterial activity. Saudi Pharm J. 24(2): 140-146.

[17]. Voleski B, and Holan ZR (1995) Biosorption of heavy metals. Biotechnolgy prog. 11(3): 235-50. 
Studies on Endophytic Fungi of Calotropis Procera (L.) R.Br. with A View to Their Antimicrobial....

[18]. Jana, S.and Pal, T.( 2007) Synthesis, characterization and catalytic application of silver nanoshell coated functionalized polystyrene beads. J. Nanosci. Nanotechnol.7, 2151-2156.

[19]. Stiufiuc, R.; Iacovita, C.; Lucaciu, C.M.; Stiufiuc, G.; Dutu, A.G.; Braescu, C.; Leopold, N. (2013) SERSactive silver colloids prepared by reduction of silver nitrate with short-chain polyethylene glycol. Nanoscale Res. Lett. 8, doi:10.1186/1556-276X-8-47.

[20]. Szmacinski, H.; Lakowicz, J.R.; Catchmark, J.M.; Eid, K.; Anderson, J.P.; Middendorf, L. (2008) Correlation between scattering properties of silver particle arrays and fluorescence enhancement. Appl. Spectrosc. 62, 733-738.

[21]. Lazar, V.( 2011) Quorum sensing in biofilms-How to destroy the bacterial citadels or their cohesion/power? Anaerobe. 17, 280285.

[22]. Donlan, R.M.; and Costerton, J.W. (2002) Biofilms: Survival mechanisms of clinically relevant microorganisms.Clin. Microbiol. Rev. 15, 167-193.

[23]. Taraszkiewicz, A.; Fila, G.; Grinholc, M.; Nakonieczna, J. (2013) Innovative strategies to overcome biofilm resistance. Biomed. Res. Int. 150653.

[24]. 24. Biel, M.A.; Sievert, C.; Usacheva, M.; Teichert, M.; Balcom, J. (2011) Antimicrobial photodynamic therapy treatment of chronic recurrent sinusitis biofilms. Int. Forum Allergy Rhinol. 1, 329-334.

[25]. Dos Santos, C.A.; Seckler, M.M.; Ingle, A.P.; Gupta, I.; Galdiero, S.; Galdiero, M.; Gade, A.; Rai, M. ( 2014) Silver nanoparticles: Therapeutical uses, toxicity, and safety issues. J. Pharm. Sci. 103, 1931-1944.

[26]. Rai, M.; Deshmukh, S.D.; Ingle, A.P.; Gupta, I.R.; Galdiero, M.; Galdiero, S.( 2014) Metal nanoparticles: The protective nanoshield against virus infection. Crit. Rev. Microbiol.. 1-11.

[27]. Evans WC.( 2005 )Trease and Evans Pharmacognosy. Saunders an Imprint of Elsevier. pp.41-7.

[28]. Alikhan I, and Khanum A. ( 2005) Medicinal and Aromatic Plants of India. Ukaaz Publication. pp. 133-4

[29]. Raghubir R, Rasik M, Gupta AJ.( 1999) Healing potential of Calotropis procera on dermal wounds in guinea pigs. J Ethnopharmacol, 68: 261-6.

[30]. Selvanathan S, Indrakumar L, Johnpaul M.( 2011) Biodiversity of the Endophytic Fungi Isolated from Calotropis gigantean (L.) R.BR. Recent Res Sci Technol, 3(4): 94-100.

[31]. Bansal P, Duhan JS and Gahlawat SK (2014) Biogenesis of nanoparticles: A review. African Journal of Biotechnology. Vol.13 (28).pp 2778-2785.

[32]. Roy Chowdhury, D.Roy, A. Chatterjee, S.K. and Roy, S.K. (2014) Study on diversity and beneficial aspects of endophytic fungi in Calotropis procera (L) R.BR, a medicinally important plant in India. Biodiversity conservation and sustainable Development: issues and Approaches Vol.I. Editor- Dr. Prithwiraj Jha by Raiganj Gour Banga Research Forum. pp147-156 (ISBN978-81-8677275-1)

[33]. Bansal P, Jaggi N, Rohilla Sk (2012) Green synthesis of Cds nanopparticles and effect of capping agent concentration on crystallite size. Res.J. Chemical Science. 2(8): 69-71.

[34]. Dobranic JK, Johnson JA, Alikhan QR.( 1995) Isolation of endophytic fungi from eastern larch (Larix laricina) leaves from New Brunswick, Canada. Can. J. Microbiol, 41:194-198.

[35]. Hata, K., and Futtai, K. (1995) Endophytic fungi associated with healthy pine needles and needles infested by the pine needle gall midge, Thecodiplosis japonensis. Can. J. Bot.73: 384-390

[36]. Radji M., Sumiati A., Rachmayani R., Elya B. (2011) Isolation of fungal endophytes from Garcinia mangostana and their antibacterial activity. Afr J Biotechnol.10(1): 103-107.

[37]. Baker S., Kumar K.M., Santosh P., Rakshith D., Satish S.( 2014) Extracellular synthesis of silver nanoparticles by novel Pseudomonas veronii AS 41G inhabiting Annona squamosa L. and their bactericidal activity. Spectrochim. Acta Part A: Mol. Biomol. Spectrosc. http://dx.doi.org/10.1016/j.saa.2014.10.033 (in press)

[38]. Coruh N; Sagdicoglu Celep A G; Ozgokee F; Dean M (2007) Food Chem.100(3), 1249-1253.

[39]. Newyork NY, Barnett HL, Hunter BB. (1972) Illustrated genera of imperfect fungi, Burgers Company, Minneapolis.

[40]. Prielo P; Pineda M; Aguilar M. (1999) Anal Biochem., 269(2), 337-341.

[41]. Krishnaraj C., Jagan E.G., Rajasekar S., Selvakumar P., Kalaichelvan P.T., Mohan N. (2010) Synthesis of silver nanoparticles using Acalypha indica leaf extracts and its antibacterial activity against water borne pathogens. Colloids Surf. B: Biointerf.76:50-56.

[42]. Rashidipour M and Heydari R. 2014 Biosynthesis of silver nanoparticles using extract of olive leaf: synthesis and in vitro cytotoxic effect on MCF-7 cells. J. Nanostruct. Chem.4:112.

[43]. Kim J. S, E. Kuk, K. N. Yu et al.,( 2007) “Antimicrobial effects of silver nanoparticles,” Nanomedicine :3(1) 95-101.

[44]. Chernousova, S.; Epple, M. (2013) Silver as antibacterial agent: Ion, nanoparticle, and metal. Angew. Chem.Int. Ed. Engl. 52, 16361653 .

[45]. Periasamy, S.; Joo, H.S.; Duong, A.C.; Bach, T.H.; Tan, V.Y.; Chatterjee, S.S.; Cheung, G.Y.; Otto, M.( 2012 )How Staphylococcus aureus biofilms develop their characteristic structure. Proc. Natl. Acad. Sci. USA, 109, 1281-1286.

[46]. Ravindra B.K., Rajasab A.H. ( 2014 )A comparative study on biosynthesis of silver nanoparticles using four different fungal species. Int. J. Pharm. Pharmaceut. Sci.6:372-376.

[47]. Kathiresan K, Manivannan S, Nabeel M.A, B. Dhivya B. (2009) Studies on silver nanoparticles synthesized by a marine fungus, Penicillium fellutanum isolated from coastal mangrove sediment. Elsevier 71,(1),133-137

[48]. Zaheer Z, and Rafiuddin.( 2012) Silver nanoparticles to self assembled films: green synthesis and characterization. Biointerfaces: $90,48-52$

[49]. Strobel G, Ford E, Worapong J, Harper JK, Arif AM, Grant DM, et al (2002) Isopestacin, a unique isobenzofuranone from Pestalotiopsis microspora possessing antifungal and antioxidant properties.Phytochemistry. 60(2): 179-183.

[50]. Bhainsa KC, D'Souza SF. (2006)Extracellular biosynthesis of silver nanoparticles using the fungus Aspergillus fumigatus. Colloids and surfaces B Biointerfaces. 47: 160-164.

[51]. Song YC, Huang WY, Sun C, Wang FW, Tan RX.( 2005) Characterization of graphislactone A as the antioxidant and free radical scavenging substance from the culture of Cephalosporium sp. IFB-E001, an endophytic fungus in Trachelospermum jasminoides. Biol Pharm Bull; 28(3): 506-509.

[52]. Sunkar S, and Valli Nachiyar C ( 2013) Endophytic fungi mediated extracellular silver nanoparticles as effective antibacterial agents . International Journal of Pharmacy and Pharmaceutical Sciences 5 (2): 95-100

[53]. Harper JK, Arif AM, Ford EJ, Strobel GA, Porco Jr JA, Tomer DP, et al.( 2003) Pestacin: a 1,3-dihydro isobenzofuran from Pestalotiopsis microspora possessing antioxidant and antimycotic activities.Tetrahedron; 59(14): 2471-2476.

[54]. Fill TP, da Silva BF, Rodrigues-Fo E.( 2010)Biosynthesis of phenyl propanoid amides by an endophytic Penicillium brasilianum found in root bark of Melia azedarach. J Microbiol Biotechnol. 20(3): 622-629. 